\title{
Time budgets of grassland herbivores: body size similarities
}

\author{
G.E. Belovsky and J.B. Slade \\ The University of Michigan, School of Natural Resources, Ann Arbor, MI 48109-1115, USA
}

\begin{abstract}
Summary. The summer (May-September) time budgets of 14 generalist herbivore species living in the same grassland environment are presented in terms of various component activities (e.g., walking, feeding, resting, etc.). All the species exhibit a decrease in activity as average daily air temperature increases. Greater body size and variety of habitats used by a species lead to increased time spent active. Use of a greater variety of habitats may increase activity time because different habitats provide suitable thermal conditions for activity at different times of the day. Body size affects an herbivore's thermal balance through metabolism, body surface area and thermal inertia. The time spent feeding, exclusive of time spent searching for foods, is less for large than small herbivores. This may arise because large species must spend more time walking in the search for food to satisfy their energy requirements. The observed feeding time differences for species composing a common trophic level in a single enrivonment may help to explain their diet choice because feeding time constrains the variety of foods an herbivore can select. Diet differences, in turn, can explain the potential competition for food if food is in short supply.
\end{abstract}

Key words: Time budgets - Herbivory - Foraging - Allometry - Grassland

The amount of time an animal devotes each day to different activities is a common measurement in behavioral ecology studies and a prerequisite for the development of time-energy budgets (Schoener 1971; Hixon 1982; Wilson 1975; Moen 1973). Time-energy budgets can be useful tools to ecologists who attempt to reconstruct a population's energy needs and/or uses and its role in the larger trophic dynamics of the ecosystem (Moen 1973). Furthermore, time-energy budgets are required in tests of optimal foraging theory and are partially predicted (feeding effort) by the theory (Schoener 1971, 1974; Hixon 1982; Krebs and Davies 1978; Belovsky 1981; Pyke et al. 1977).

Detailed development of time-energy budgets often involves investigating budgets by sex, age and social status subgroups, as well as by habitat and seasonal differences (Moen 1973). In some instances, detailed studies of the thermal-environmental determinants of time budgets have been attempted with varying degrees of predictive success (e.g., Porter et al. 1973, 1975; Morhardt and Gates 1974; Morhardt 1975; Gates 1980; Montieth 1973; Moen 1973; Be-

Offprint requests to: G.E. Belovsky lovsky 1981, 1984b; Tracy 1975; McNab 1963). As season and habitat utilization affect time budgets, these factors might be expected to be related to thermal regulation, which, at least in part, is a function of body size (Gates 1980). Therefore, the idea of predicting time budgets using a comparative approach was examined.

To examine the influence of body size on time budgets and their potential limitation by thermal conditions, behavioral observations were made on 14 species of generalist herbivores at a single prairie site during summer (MaySeptember). The herbivores ranged in body mass from $2.8 \times 10^{-4}$ (based on relative abundances of grasshoppers) to $636 \mathrm{~kg}$ for an average adult. The time-budget data for this set of species were used to address three questions:

1) Does the time spent in various activities change with body mass?,

2) Does the time spent in some activities depend upon the thermal environment, and if so, is this relationship related to body mass?

3) If body-mass relationships emerge, are they related to other allometric correlates of energy use?

\section{Study site}

Observations for the time budgets were carried out at the National Bison Range, Montana. This 9,000 ha enclosed area varies in elevation from 820 to $1,500 \mathrm{~m}$ and primarily consists of Palouse prairie of the northern intermountain west. The vegetation is composed of $70 \%$ grasses, $20 \%$ forbs, and $10 \%$ woody vegetation by standing crop biomass. The dominant grasses are Agropyron spicatum, Festuca idahoensis, Festuca scabrella and Poa pratensis, dominant forbs are Lupinus sp., Achillia macrofolia and Balsamorrhiza sagittata, and dominant woody plants are Artemisia frigida, Symphoricarpos occidentalis, Rosa sp., Pseudotsuga menziesii and Pinus ponderosa. Although grassland communities dominate the area, portions of the site are open forest or shrub communities at higher elevations or along drainages where moisture is greater.

The Bison Range is inhabited by a diverse group of generalist herbivores that are easily viewed from roads or by walking through the area. These species include the bison (Bison bison), elk (Cervus elaphus), bighorn sheep (Ovis canadensis), mule deer (Odocoileus hemionus), white-tail deer (Odocoileus virginiamus), pronghorn antelope (Antilocapra americana), yellow-bellied marmot (Marmota flaviventris), Rocky Mountain cottontail (Sylvilagus nuttalli), Columbian ground squirrel (Spermophilus columbianus), meadow vole (Microtus pennsylvanicus), and four common orthopterans 
(Dissosteira carolina, Circotettix undulatus, Melanoplus sanguinipes and $M$. femur-rubrum). These were the most common herbivores and were the 14 species examined in this study.

\section{Methods}

For the period of May through September during 1978-1982, behavioral observations were made on the 14 above-named herbivores as part of a comparative foraging study. Measurements involved three types of observations: observation of focal individuals over long-term ( $\geqq 6 \mathrm{~h}$ ) and short-term $(<6 \mathrm{~h})$ time periods, and periodic scans (each $15 \mathrm{~min}$ ) which determined the behavior at a particular instant for each of a set of visible animals. Each of these observational methods provides some behavioral values that can be documented by the other methods, as well as unique values. All measurements were made at a distance less than $100 \mathrm{~m}$ for species $>2.5 \mathrm{~kg}$, less than $20 \mathrm{~m}$ for species between 0.3 and $2.5 \mathrm{~kg}$ and less than $1 \mathrm{~m}$ for smaller species.

Frequently, the long-term focal observations failed to exceed six $h$ duration because the focal animal wandered out-of-sight or further away from the observer than the prescribed distance for observation (see above). However, these observations [short-term $(<6 \mathrm{~h})$ focal observations] were used in combination with successful long-term observations and periodic scans of instantaneous behaviour to compute averages for the frequency of different behaviors, outlined below.

All three observational methods were applied equally to each $\mathrm{b}$ of the 24-h daily period to insure an unbiased sample of the daily incidence of each behavior for each species. Nevertheless, it was not always possible to acquire observations at every $h$ for each species. Some species were not active above ground at all h ( $M$. flaviventris, $S$. columbianus and $M$. pennsylvanicus) or were buried in the litter (grasshoppers), making observations at those times impossible. Even for some species that are always above ground, it was impossible to acquire observations during all nocturnal h, even with the use of spotlights, starlight scopes, or moonlit nights. This was particularly true for solitary species inhabiting denser shrub communities $(O$. virginianus, $O$. hemionus, $S$. nuttalli).

On a given day, one of the 14 species was chosen for observation using one of the three observational techniques. For species smaller than $3.0 \mathrm{~kg}$, the observer could go to specific sites known to be inhabited by the species and locate individuals for observation by walking through the area. For larger species, the observer drove the roads in the study area until an individual or groups of individuals of the appropriate species were found, and the animal(s) was then observed from the vehicle or followed on foot.

The above procedures were employed for all species studied except $M$. pennsylvanicus, which were observed in terraria $\left(0.2 \mathrm{~m}^{2}\right.$ floor $)$ containing sod from the study site (see Belovsky 1984a for greater detail). These terraria were maintained out-of-doors to simulate the natural thermal environment. Captive studies were necessary since $M$. pennsylvanicus could not be observed directly in the wild due to their rapid movements in dense grass.

Observations were restricted to adults in an attempt to minimize differences due to age. During all observations (long-term, short-term and periodic scans for instantaneous behavior), a number of behaviors were recorded. When applicable, behaviors were categorized for the 14 species by the following scheme:

A) Active:

1) walking but not involved in feeding

2) running (except Microtus and grasshoppers)

3) socially interacting (except Microtus and grasshoppers)

4) feeding

a) cropping food

b) moving between plants

B) Inactive:

1) lying (except Microtus and grasshoppers)

2) standing

3) ruminating (for ruminant species only).

During long-term and short-term observations, these behaviors were recorded on a continuous basis for the focal individual using stopwatches and, if needed, binoculars or a spotting scope. These observations were recorded either in a notebook or on a tape recorder. During periodic scans, the number of individuals exhibiting each behavior was recorded at $15 \mathrm{~min}$ intervals. Finally, every $30 \mathrm{~min}$ during all types of observations, the aspect (compass direction) of the slope on which each individual was located was recorded.

In addition, the number of defecations and urinations was counted during focal observations for all but the grasshoppers, Microtus, ground squirrel, cottontail and marmot. The feces were collected after the observation period, dried and weighed. Fecal and urinary (except grasshoppers) outputs were measured for the smaller species $(\leqq 2.5 \mathrm{~kg})$ by collecting the daily output of individuals maintained in cages with ad libitum food and water. Also, during longterm observations of ruminants, the duration of a feeding bout (period of feeding uninterrupted by rumination or resting) was related to the previous and subsequent time spent ruminating.

Using the behavioral observations from the long-term focal method, the feeding time for each species on specific days was related to the average daily air temperature (the mean of the day's maximum and minimum air temperatures). The air temperatures were available from a weather station located at the Bison Range headquarters. Sufficient observations to perform this comparison were available for 11 of the 14 species. An average summer daily feeding time was measured from the scan observations conducted over the entire study.

\section{Results}

Table 1 presents the body mass, sample size and average daily proportion of time spent in different activities for each species. The proportional time-budget values do not have to total $100 \%$ for each species because some behaviors can occur simultaneously (e.g., rumination can occur while lying or standing, walking can occur while feeding). These behavioral values are based upon the aggregate of longterm, short-term and periodic scan observations, normalized so that each $h$ within the 24-h day, if sampled, is equally represented. This avoids the biases of oversampling certain times of the day. Also presented is the percentage of time spent by each species on the most commonly used aspect (compass facing of the slope) during all observations of 
Table 1. Summary of time budget data for each of 14 National Bison Range herbivores

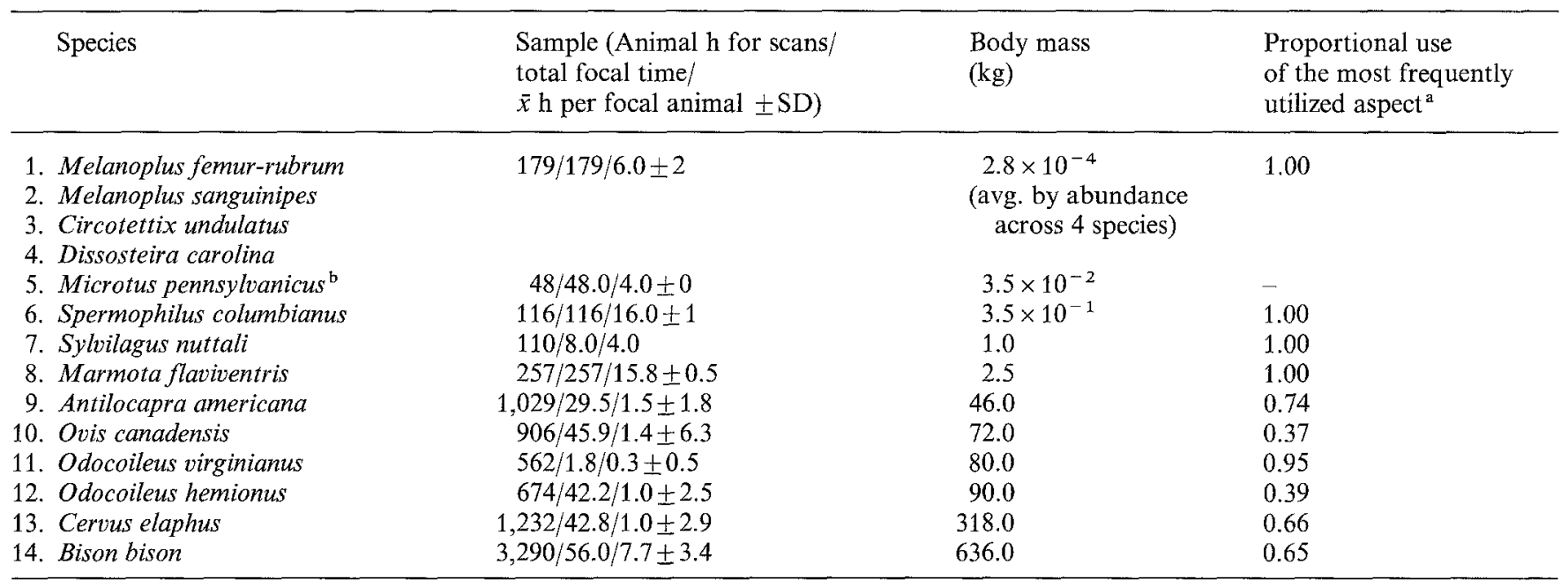

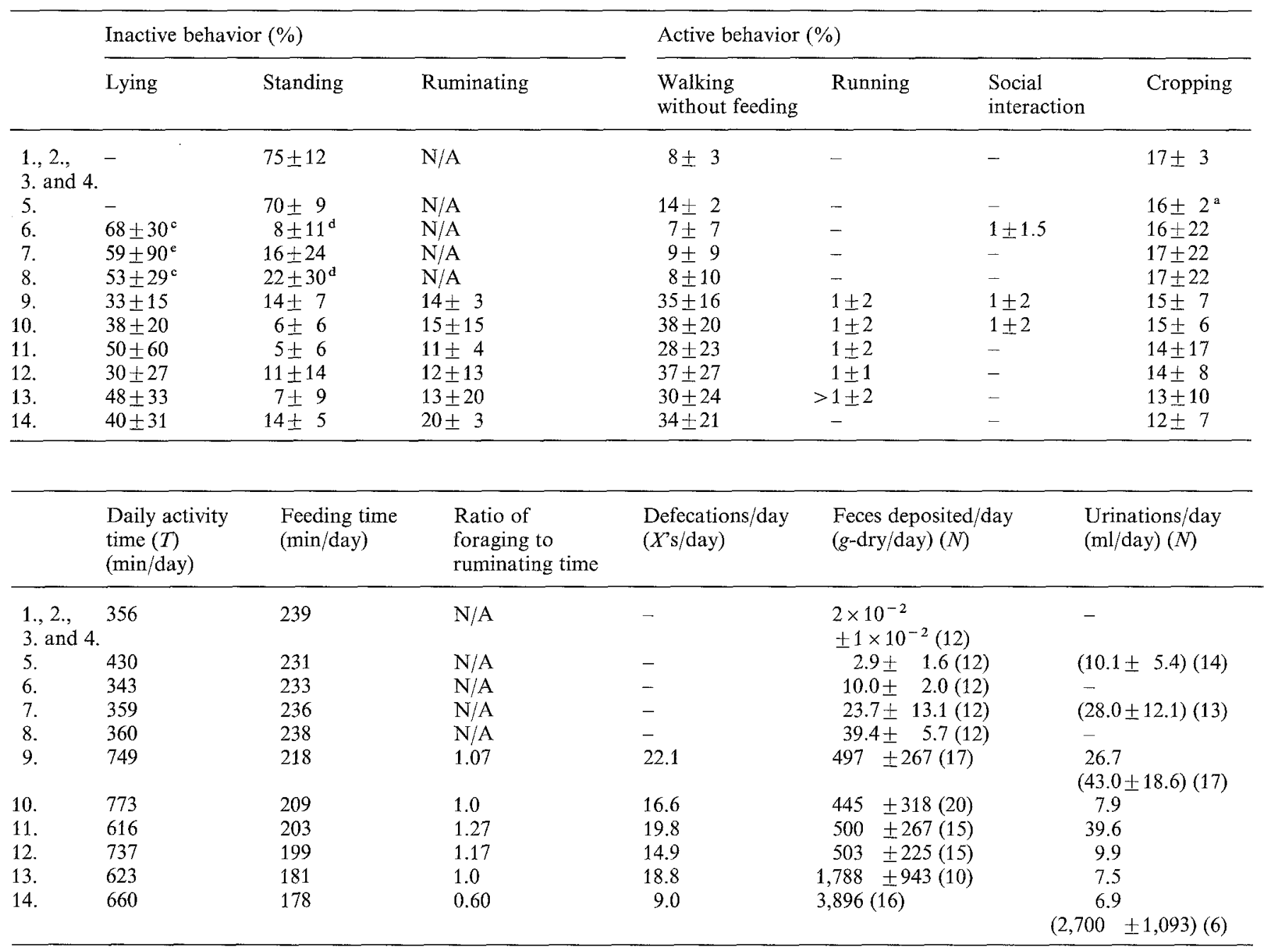

N/A not applicable

- Not observed

a Proportional use of the most commonly utilized aspect

b Based on observations in terraria

c Only includes above-ground observations

d Includes sitting on burrow and standing on hindlegs looking for predators

e Assumed synonomous with resting in brush 


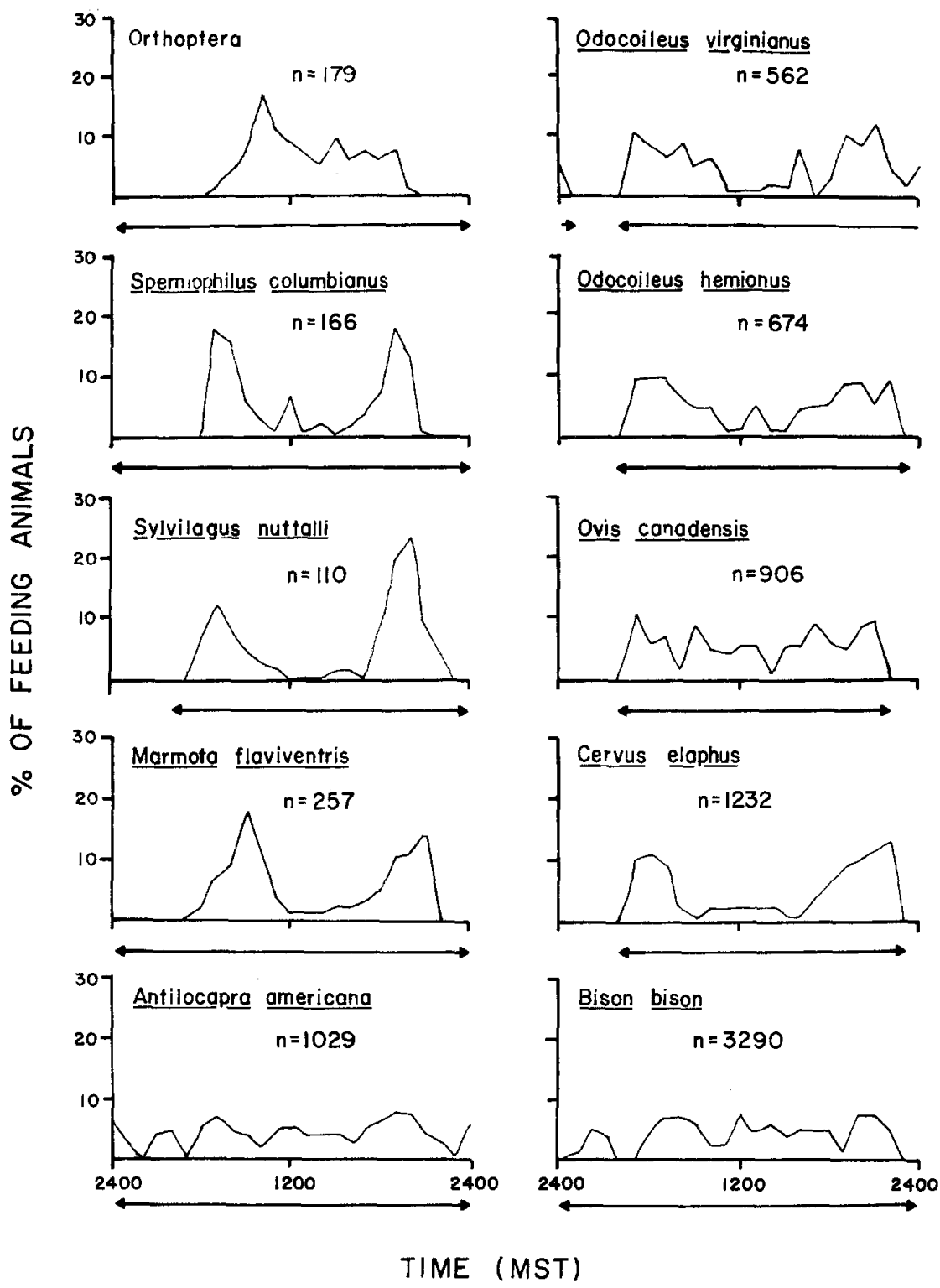

Fig. 1. Plots of activity cycles are presented for 13 herbivores (Orthoptera represent 4 species, see text) at the National Bison Range, Montana, during June-September. The percentage of total daily activity observed at each $h$ is plotted for each $h$. The period for which observations were available is marked with a bar. The samples sizes (n) presented on the plots refer to animal-h of observation the species. Aspect use should reflect the dependence of the herbivore on certain thermal environments since solar radiation, humidity, and wind speed vary with aspect. Also, vegetative communities change with aspect.

The time-budget data for the four species of grasshoppers were pooled because no differences could be discerned. The only differences observed in their activity patterns were minor variations in the time of day that activities took place. Smaller species ( $M$. femur-rubrum and $M$. sanguinipes) tended to become and remain active at cooler times (morning and evening) while the larger species ( $D$. carolina, C. undulatus) tended to remain active at hotter times (midday). These differences, however, were usually less than $15 \mathrm{~min}$ and at most $30 \mathrm{~min}$ and, therefore, appeared inconsequential to the analysis.

Figure 1 presents the percentage of time that each species spends in active behaviors at each $h$ of the day. These data are presented for all species, except $M$. pennsylvanicus, because this species was studied under captivity rather than in the field. Hours for which data were obtained are marked by horizontal arrows below each graph. The data were used to compute the average daily activity time $(\mathrm{T})$ for each species:

$T=\sum_{i}^{24 \mathrm{~h}} p_{i}(60 \mathrm{~min} / \mathrm{h})$

where $p_{i}$ is the percentage of $\mathrm{h} i$ spent active as taken from scan observations. $p_{i}$ was computed from observations taken from periodic scans using method B (Appendix) for $M$. femur-rubrum, $M$. sanguinipes, $C$. undulatus, D. carolina, $A$. americana, $O$. hemionus, $O$. canadensis, $C$. elaphus, and B. bison; method C.1 (Appendix) was used for S. columbianus and $M$. flaviventris; and method C.2 (Appendix) was used for $S$. nuttalli and $O$. virginianus. These computed $\mathrm{T}$ values appear in Table 1.

Using only long-term focal observations of 6 or more $\mathrm{h}$ duration, for which observations of $12 \mathrm{~h}$ or longer were used (except for grasshoppers since they are only visible at the warmer times of day), the time spent in active behaviors by a species on a given day $(\mathrm{T})$ was estimated as:

$T=\frac{t(24 \mathrm{~h})}{d}$ 


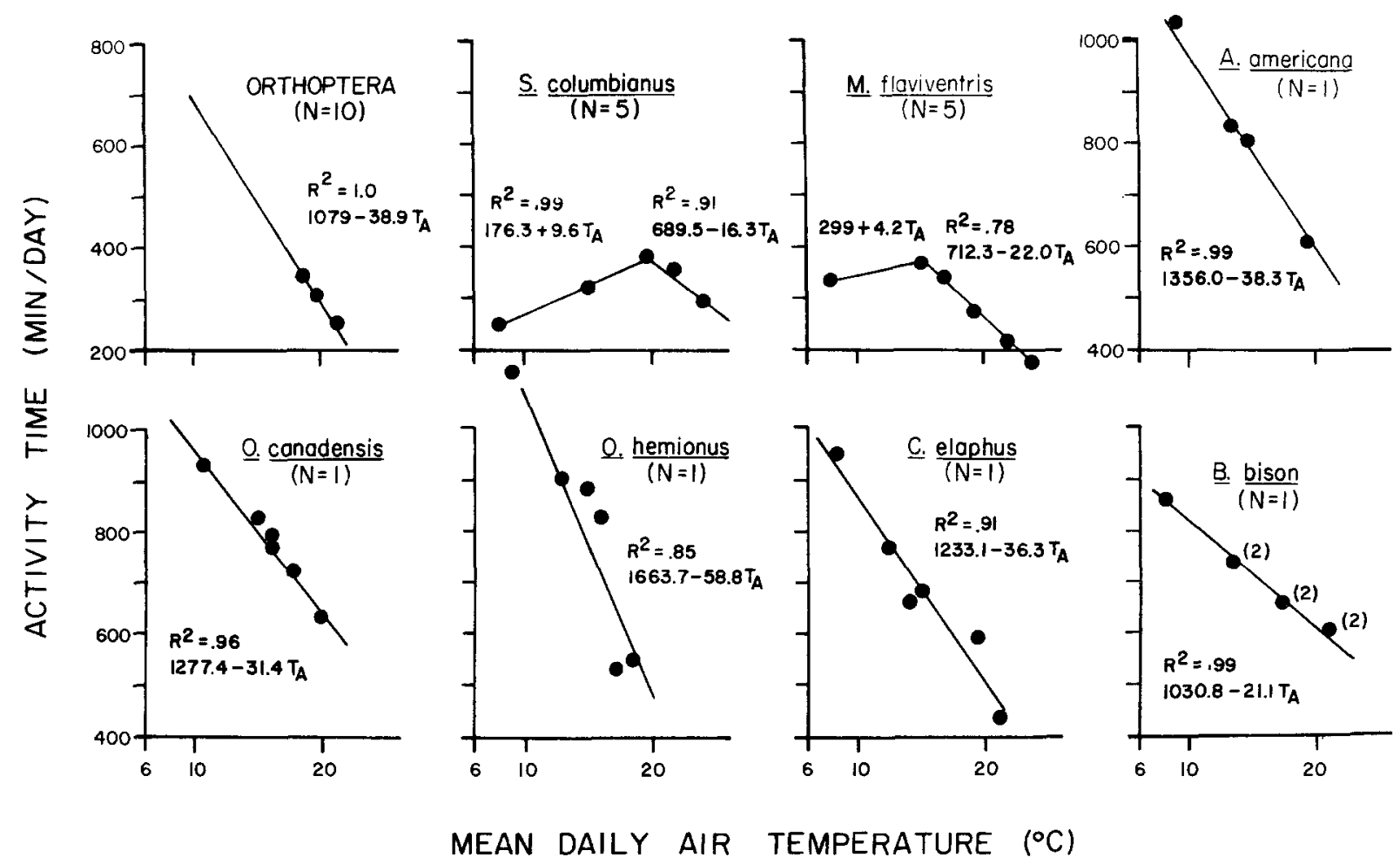

Fig. 2. Plot of average daily air temperature (see text) and activity time for 11 herbivores at the National Bison Range during JuneSeptember. The 4 grasshopper species are plotted as one (Orthoptera) because no differences in their activity times were observed (see text). The $\mathrm{N}$ term refers to the number of individuals observed for each sample point

where $t$ is the time spent in active behaviors (min) during the observations, and $d$ is the duration of the observation (h). Figure 2 contains the measured $T$ values and the average daily temperature for the observation day for 11 herbivores (the 4 grasshoppers are combined as one group because no differences in their time-budget data were discerned, see above). All 11 herbivores demonstrate a decline in their daily time spent active as the daily air temperature increases. Over the daily air temperatures observed in summer, only two species (Marmota flaviventris, and Spermophilus columbianus) demonstrate a decline in activity at the cooler air temperatures. Interestingly, these two species are the only two hibernators.

\section{Discussion}

A logical unifying concept to employ in comparing the different herbivores' time budgets is body size. Peters (1983) argues that many behaviors should be related to body size and this is a little-studied aspect of behavioral ecology. The rationale for the potential relationship between many behaviors and body size is the underlying physiology that scales with size.

Table 2 contains the Spearman Rank correlations between body mass and the different behavioral measurements presented in Table 1. Rank correlation was used, rather than a parametric measure of association, for several reasons (Conover 1971). First, the variables were correlated in a non-linear fashion. Second, the non-linear relationship is not known a priori. And, third, the range of values for the dependent variables is often small, which might lead to an underestimate of parametric measures of association. Nine of 14 comparisons were statistically significant. Of
Table 2. Summary of Spearman Rank Correlations (R) for various time budget categories and different independent variables and their significance $(P)$

\begin{tabular}{|c|c|c|c|}
\hline Behavior & $\begin{array}{l}\text { No. of } \\
\text { species }\end{array}$ & $R$ & $P$ \\
\hline Time active $(\min / \mathrm{d})$ : & 11 & 0.68 & 0.02 \\
\hline Feeding time $(\min / \mathrm{d})$ : & 11 & -0.91 & 0.001 \\
\hline $\begin{array}{l}\text { Active behaviors }(\%) \text { : } \\
\text { Walking } \\
\text { Running } \\
\text { Cropping }\end{array}$ & $\begin{array}{r}11 \\
5 \\
11\end{array}$ & $\begin{array}{l}0.68 \\
0.0 \\
-0.98\end{array}$ & $\begin{array}{l}0.02 \\
\text { n.s. } \\
0.001\end{array}$ \\
\hline $\begin{array}{l}\text { Inactive behaviors }(\%) \text { : } \\
\text { Lying } \\
\text { Standing } \\
\text { Ruminating } \\
\text { Ruminating time (min) }\end{array}$ & $\begin{array}{r}9 \\
11 \\
6 \\
6\end{array}$ & $\begin{array}{r}-0.63 \\
-0.58 \\
-0.14 \\
0.49\end{array}$ & $\begin{array}{l}0.05 \\
0.05 \\
\text { n.s. } \\
\text { n.s. }\end{array}$ \\
\hline $\begin{array}{l}\text { Foraging/rumination: } \\
\text { (bout) } \\
\text { (time) }\end{array}$ & $\begin{array}{l}6 \\
6\end{array}$ & $\begin{array}{l}-0.54 \\
-0.60\end{array}$ & $\begin{array}{l}\text { n.s. } \\
\text { n.s. }\end{array}$ \\
\hline Defecation $(\mathrm{g} / \mathrm{d})$ : & 11 & 0.99 & 0.001 \\
\hline Defecation rate $\left(X^{\prime} \mathrm{s} / \mathrm{d}\right)$ : & 6 & -0.71 & 0.05 \\
\hline Urination rate $\left(X^{\prime} \mathrm{s} / \mathrm{d}\right)$ : & 6 & -0.71 & 0.05 \\
\hline
\end{tabular}

the five nonsignificant relationships, four deal with body size and rumination time for the six ruminant species, and the fifth is for time spent running. The most important relationships to be explained deal with activity and feeding time as functions of body size. 
Daily activity time. Activity time significantly increases with body size. Why should activity time increase with size? The explanation may lie with differences in the herbivores' thermal regulation. A significant negative relationship exists between average daily air temperature and daily activity time for the 11 species for which long-term focal observations could be made in the field (Fig. 2); as it becomes warmer, activity declines.

Average daily air temperature is not a complete description of the thermal environment which also depends upon the combination of solar radiation, wind velocity, air temperature, and other factors at each time period during the day. It, however, does provide a useful first approximation for these other values that are not as easily measured or integrated together. Similar correlations between daily activity time and average air temperature have been found for other herbivore species (e.g., Alces alces, Belovsky 1978; Lepus americanus, Belovsky $1984 \mathrm{c}$; Castor canadensis, Belovsky 1984d; Orthoptera: Chappell 1983; Parker 1982; Stower and Griffiths 1966). Therefore, activity time appears to be dependent upon thermal balance.

Aspect use in a prairie environment (Table 1) is an important factor in thermoregulation because of its influence on solar radiation, humidity and wind velocity encountered by an organism. This is particularly important in a prairie environment where cover in different vegetative habitats is not sufficient to be of major consequence for thermal regulation. Consequently, animals should use different aspects to thermoregulate behaviorally. Species that use a variety of aspects should have greater activity time than species that are more restricted in their aspect use. This arises because the different aspects will provide suitable thermal conditions for activity as thermal conditions change (e.g., time of day and different days). This correlation is indeed observed (Spearman Rank Correlation: $R=-0.84, N=10$, $P<0.001$ ).

The major reason for the very strong influence of aspect on activity time may arise from its almost dichotomous action: small $(\leqq 2.5 \mathrm{~kg})$ herbivores are resident on a very small area (mean aspect use $=1.0 \pm 0.0, n=4$ ), but larger herbivores $(>2.5 \mathrm{~kg}$ ) range over a much wider area (mean aspect use $=0.63 \pm 0.22, n=6$ ). This means that aspect use tends to be either employed or not, which might be a function of increasing mobility with body size, the topography of the environment, and distance between different aspects.

Large animals should be more mobile than small animals, primarily due to their greater speed of locomotion arising from greater stride length (Bonner 1965; Peters 1983). Therefore, the observed positive correlation between body size and activity time may be due to the greater ability of large animals to use a variety of aspects; a significant rank correlation does exist between body mass and time spent walking (Table 2).

To address the interaction of several factors on activity time, multiple regression must be used since non-parametric rank correlations do not permit a statistical analysis of partial correlation to address the importance of different variables (Conover 1971). The independent variable could be fit to each dependent variable using arithmetic, power, exponential and logarithmic regression models. The regression model providing the best fit can then be assumed to provide the best description of the relationship between the dependent and independent variables. This, however, does not provide an a priori mechanistic model of how these
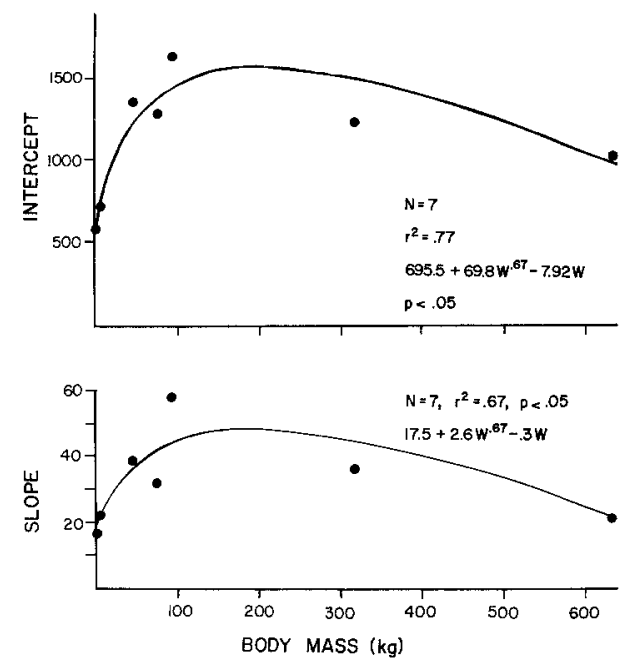

Fig. 3. The slopes and intercepts for the functions relating average daily air temperature with daily activity time (Fig. 2) are plotted against the animal's body mass. Only data on endothermic species are presented. The regression equations for these relationships are also presented

biological factors operate. Therefore, a theoretically expected relationship between the independent and dependent variables was employed at the transformations in the multiple regression.

From models of thermal physiology, three important dynamics are important (Bakken and Gates 1975; Gates 1980; Montieth 1973). First, the animal's surface area $\left(\alpha\right.$ mass $^{0.67}$ ) partially determines the amount of environmental heat absorbed by the animal, and the amount of heat radiated and lost by convection to the environment. Second, the amount of heat produced metabolically by the animal may also be related to surface area. Third, the animal's thermal inertia, the ability to store heat and warm up, should be a function of body mass $\left(\alpha\right.$ mass $\left.{ }^{1.0}\right)$. Each of these factors can operate to be beneficial or detrimental to the animal's thermal balance. Therefore, the expected influence (net heat gain or loss) for each factor cannot be predicted a priori. Both Peters (1983) and Calder (1984) employ these relationships to examine the role of body size on various aspects of thermal physiology.

Using the above thermal relationships for the exponents of body mass (W), multiple regression methods were employed to fit the relationship:

$y=a+\mathrm{bW}^{0.67}+\mathrm{cW}^{1.0}$

where $\mathrm{a}, \mathrm{b}$, and $\mathrm{c}$ are constants and $\mathrm{y}$ is the slope or intercept for the functions defining daily activity time versus average daily air temperature (Fig. 2). The regression model provides a very good fit (Fig. 3). The ectotherms (the four grasshopper species) were deleted from the analysis because their inclusion with the endotherms should bias the regression. Using non-linear regression techniques (Marquardt 1963; Glass 1967), the same function was fit to the data, but the exponents of body mass were also allowed to vary. In this case, similar exponents were generated, 0.79 vs. 0.67 and 0.92 vs. 1.0 , which are not significantly different from the expected values and the variance explained increased by less than $10 \%$.

With the multiple regression model for body mass, the role of body mass and aspect use on the functions relating 
daily air temperature and activity time (Fig. 2) can be investigated. Partial correlation coefficients indicate that body mass (W) and aspect use (A) are both important for the intercept of the daily average air temperature versus activity time function (partial correlation coefficients: $r_{\mathrm{W}}=0.63$, $r_{\mathrm{A}}=-0.50$ ). For the slope of the function, only body mass is important (partial correlation coefficient: $r_{\mathrm{W}}=0.62, r_{\mathrm{A}}=$ -0.08 ). None of the partial correlation coefficients are statistically significant because of the small sample size, 7 species (Orthoptera are excluded). These results, however, indicate that aspect use is important to set a general value for activity time (the intercept), but the effect of body mass on thermal physiology is solely responsible for how this value changes from day to day with changing environmental conditions.

Combining the roles of body mass and activity, a multiple regression model for average daily activity time is obtained:

$T=696.1-2.1 \mathrm{~W}+19.5 \mathrm{~W}^{0.67}-334.1 \mathrm{~A}$

$\left(r^{2}=0.87, n=10, P<0.01\right)$. Body mass and aspect use appear equally important in terms of the variance explained (partial correlations: $r_{\mathrm{w}}=0.71, r_{\mathrm{A}}=-0.65, P<0.1-0.05$ ). Therefore, body mass appears to affect thermal physiology and the ability to thermoregulate behaviorally by the animal's moving between different aspects.

Daily feeding time. One might expect daily feeding time to increase as activity time increases. This is observed for each species, if their activity times from long-term focal observations (Fig. 2) are correlated with their observed time spent feeding (correlation coefficients average $0.99 \pm 0.05$ for the 11 species). Therefore, in a similar manner as observed for the activity time above, an herbivore's feeding time declines as the thermal conditions become warmer.

When the observed average daily feeding times for the 14 species are rank correlated with body mass, a significant negative association is found (Table 2), unlike the observed relationship for daily activity time. Therefore, the proportion of time spent feeding while active is declining with increasing body mass, even though feeding time increases with activity for each species. What causes this discrepancy?

If activity time increases with the use of various aspects, this does not necessarily lead to increased feeding time because all of the different aspects used may not contain suitable vegetation for feeding. This resulting increase in activity time could be in nonforaging activities such as behavioral thermoregulation, walking, grooming, etc. The observed decrease in feeding time as body mass increases might be caused by increased time spent walking in search of food (Table 2). Why should large animals spend more of their activity time walking? One possibility is their greater use of different aspects which requires movements between habitats (Spearman Rank Correlation: $R=-0.87, N=10, P<$ 0.001 ).

A foraging explanation for increased walking is also available. Large animals may need to walk more to find the large amounts of food they require. Given a certain density of food, large animals will need to walk over larger areas to acquire a sufficient quantity of food. Furthermore, if food is patchily distributed, the large animal will have to move between more patches each day which will increase walking time.

In walking more to find food, the herbivore might visit many different aspects simply by chance, i.e., aspect use other than as behavioral thermoregulation may be due to feeding movements. Comparison of these two explanations for aspect use cannot be made in a simple fashion without observing animals feed under conditions where food and aspect distributions are varied. Nonetheless, random use of aspects was not observed since the herbivores select different aspects at different times of the day, and each species failed to use the different aspects in their proportional availability (unpubl. data). Therefore, both explanations may be operative.

If feeding energetics are important, then a portion of walking time (L) should be proportional to:

$\frac{(M-C d) d}{P S}$

where energetic requirements for maintenance $(M)$ and 1ocomotion (C) are proportional to $\mathrm{W}^{0.69}$ (Calder 1984), d is the distance between food patches, $P$ is the food biomass per patch and $S$ is the animal's maximum speed while walking which is proportional to $\mathrm{W}^{0.38}$ (Peters 1983). The above expression estimates the fraction of walking due to foraging energetics as proportional to $\mathrm{W}^{0.31}$.

Using the multiple regression methods discussed above with the relationships for body mass and aspect as independent variables, the following regression function is found:

$L=349.6-311.6 \mathrm{~A}+14.2 \mathrm{~W}^{0.31}$

$\left(r^{2}=0.85, N=10, P<0.001\right.$; partial correlation coefficients: $\left.r_{\mathrm{A}}=0.81, P<0.01 ; r_{\mathrm{W}}=0.50, P<0.10\right)$. In the multiple regression, aspect use is by far most important, explaining $62 \%$ of the variance, while the movement between feeding patches accounts for $23 \%$.

If activity time is considered a fixed value (average daily activity for each species), then as expected, foraging energetics appear most important to the quantity of feeding time the herbivores have:

$T_{F}=243.5-9.5 \mathrm{~W}^{0.31}$

$\left(r^{2}=0.95, N=10, P<0.001\right)$. Therefore, daily activity time for these herbivores appears to be a function of thermal physiology (body mass dependent) and behavioral thermoregulation (aspect use dependent). The daily activity time increases as the herbivores become larger and use more aspects. As activity time for a species increases so does its feeding time, but feeding time declines as body mass increases because large herbivores must spend more of their potential feeding time searching for food.

Other activities. The lack of a good correlation for various aspects of ruminating and body mass is surprising since large ruminants are known to ruminate longer than small ruminants relative to feeding time. This occurs because large herbivores tend to consume foods of higher fiber content (Hungate et al. 1959; Moen 1973; Demment and Van Soest 1981). The failure to observe this relationship is inexplicable and may be due to a small sample size $(N=6)$.

As expected the larger species defecate more ( $\mathrm{g} /$ day) than smaller species, because larger individuals consume more food than smaller individuals. The rates of defecation and urination (X's/d), however, decrease with body size. This is expected in part since the mass of feces and urine increases with body mass to the 0.86 power, while digestive capacity increases with mass to the 1.0 power (Belovsky 
1986a; Demment 1982), providing an expected excretion rate proportional to body mass to the $\mathbf{- 0 . 1 4}$ power. This results from lower digestive turnover rates in large herbivores. The observed excretion rate is proportional to body weight to the -0.25 power for feces and -0.05 for urine, which are not significantly different from -0.14 given the small sample sizes.

The daily cycle of activity. The time of day when the herbivores are active may be different even though they may have similar total activity times. The activity cycles in Fig. 1 are statistically different. This was determined using $\chi^{2}$ contingency tables where the $\chi^{2}$-table cells contain the total number of individuals of a species that were active at a given $\mathrm{h}$ period. The analysis was restricted to the data from scan samples between $0500-2200$, the $\mathrm{h}$ equally sampled in the study. Even though the daily cycles are different, similarities are evident.

To test for similarities, the Euclidean distances (D) between activity cycles (restricted to $0500-2200 \mathrm{~h}$ ) are measured:

$D_{i, j}=\sqrt{\sum\left(p_{k, i}-p_{k, j}\right)^{2}}$

where $i$ and $j$ are two different species, $k$ is the $\mathrm{h}$ and the $p$ values refer to the fraction of total activity occurring in a given $h$ for each species. The smaller the $D$ value, the greater the similarity between two species' activity cycles. The similarity in two species' body sizes was measured as the ratio of their body masses (Table 1), and the similarity in their aspect use was measured as the absolute value of the difference between their aspect use values (Table 1).

Similarity in body size (ratio of masses) is found to be correlated with the species' similarity in activity, as measured by the Euclidean distance (Spearman Rank Correlation: $R=0.80, N=45, P<0.001)$ and is expected if body mass is an important aspect of thermal physiology. Differences in aspect use are not important $(R=-0.03, N=45$, n.s.). Also, taxonomic affinities are demonstrated, since cervids and bovids, differing in body size, are more closely related to co-family members than to non-related but similar-sized herbivores. This would be expected to arise from similarities in thermal physiology for closely related species.

\section{Conclusion}

The importance of body size in activity patterns is expected because of metabolic, thermoregulatory and predation considerations. An animal's energy demands for maintenance, locomotion, and other activities appear to be functions of body mass (Peters 1983; Calder 1984). These energetic costs have been suggested to influence an organism's investment in time for various activities. These claims are often contradictory, hypothesizing that large animals must spend more time feeding to satisfy their larger energy needs or large animals cannot be as active as small animals, because their energy costs for locomotion are greater (Peters 1983; Calder 1984).

Thermoregulation might limit activity because certain times of day and habitats might present excessive heat gains or losses to the animal. The determinants of instantaneous heat flow for an organism are body size dependent (metabolism, surface area, convection coefficients, evaporative heat flux, etc.), as is long-term heat storage (Gates 1980). At least 11 herbivores $(9$ mammals and 2 insects) are known to be limited in their activity and feeding time by heat budgets (Belovsky 1981, 1984a, 1984b; Belovsky 1986b; Stower and Griffiths 1966; Finch 1972a, b).

Susceptibility to predation may reduce an organism's activity or influence when it is active, if activity increases the likelihood of being captured. Small animals are known to be more susceptible to predation, as there are more species that can consume them. Therefore, predation may determine activity patterns for some animals, particularly small species.

Of the three hypotheses for activity patterns, thermoregulation appears most important for the animals studied here, and energetic considerations for feeding movements are of secondary importance. Predation was not directly addressed but the large amount of variance explained by the other two explanations would suggest that predation is of minimal importance.

Aspect use influences thermoregulation and, thereby, affects activity time and cycles; it is an important determinant of activity and walking time, but appears of little importance for daily activity cycles. Interdependence of thermoregulation and habitat use is known for other herbivores (Belovsky 1981, 1984b).

Body mass is important in determining the thermal physiology of the animal. At least for the warm summer conditions studied here, size appears to affect activity time in a complex manner. The intercept of the function relating average daily air temperature to activity time is greater for intermediate-sized herbivores $(\sim 90 \mathrm{~kg})$, while the negative slope of the function is smaller for small and large herbivores. Therefore, this is not a simple case of one body size providing the greatest activity time, rather as thermal conditions change, different body sizes possess advantages. Body size also is related to the amount of time the herbivore must spend searching for food because of energetic considerations, with more search time required by large animals.

Differences in feeding time for herbivores of different sizes in the same environment may have important consequences for competitive interactions for food. The periodicity of activity or foraging should have little impact on exploitative competition, since an herbivore's consumption of a plant removes the food for use by another herbivore, regardless of time of day (Schoener 1974). Differences in periodicity do influence interference competition, but there is little evidence for interference between these species (McCollough 1980). Feeding time, however, constrains diet choice by these species (Belovsky 1986b), and this determines the degree to which different herbivores seek the same food plants (Belovsky 1984c, 1986b). Therefore, although the time budgets impact upon these species' behavior and diet choice (Belovsky, 1986 b), it may also have consequences for their ability to competitively coexist if food is limiting (Belovsky 1984c, 1986a).

Acknowledgments. We wish to thank J. Marshall and J. Hogg for their help in collecting data and the personnel of the National Bison Range, Montana, for their belp. We thank S.L. Lima, M.E. Ritchie, and P.W. Webb for critically reading early drafts of this paper and supplying helpful comments. The work was supported by NSF grant DEB-78-02069 A01 to G.E. Belovsky and T.W. Schoener, and grants to G.E. Belovsky from the Harvard Society of Fellows and the Richmond Society, Harvard University. 


\section{Appendix}

Equivalence of different activity measurements for computing activity time.

A) If we measure the time an animal spends in active behaviors directly, the following information is available:

$t_{i j}=$ time an animal was observed in active behaviors in $\mathrm{h} i$ during observation $j$

$k_{i j}=$ total time an animal was observed in all behaviors in $\mathrm{h} i$ during observation $j$

$p_{i}=$ the proportion of time in $\mathrm{h} i$ spent in active behaviors or

$\sum_{j} t_{i j} / \sum_{j} k_{i j}$

which gives daily time spent in active behavior $(T)$ as:

$T=\sum_{i}^{24 \mathrm{~h}}\left(\sum_{j} t_{i j} / \sum_{j} k_{i j}\right)(60 \mathrm{~min} / \mathrm{h})$

when $\mathrm{T}$ is measured in minutes.

B) Often it is too difficult to observe animals for extended periods because they may wander out of view, become disturbed by the observer's presence, etc. In these cases, it may be more expedient and appropriate to take instantaneous observations during a period for a number of individuals, e.g., categorizing the behaviors of individuals observed in an area scanned at regular time intervals. The use of these observations leads to the following modifications:

$n_{i j}=$ the number of individuals observed performing active behaviors in $\mathrm{h} i$ of observation $j$,

$m_{i j}=$ the total number of individuals observed in $\mathrm{h} i$ of observation $j$.

$n_{i j}$ and $m_{i j}$ can be substituted for $t_{i j}$ and $k_{i j}$ above, since $n_{i j}$ and $m_{i j}$ are respectively the limits of $t_{i j}$ and $k_{i j}$, as $k_{i j}$ approaches zero.

C) It may be impossible or imprecise to measure $m_{i j}$ because the animals are not readily visible when not engaged in active behaviors. This condition can commonly occur if the animal is subterranean when inactive or hidden in very dense vegetation when inactive. However, if we know the population density of the animal in the area observed $(m), m$ can be substituted for $m_{i j}$. Given that $m$ is often difficult to measure, several approximations for $m$ can be used:

1) If the population is restricted to a small visible area (e.g., marmot colony, ground squirrel colony, etc.), $m$ can be substituted by the maximum number observed in any one observation period.

2) If approximately the same area is censused each period (e.g., same area is scanned by the observer, the same road is driven, etc.), the maximum number observed in any one observation period can be used as an approximation of $m$.

Both approximations require a large number of observation periods to insure that $m$ is not underestimated, thereby overestimating $T$.

\section{References}

Bakken GS, Gates DM (1975) Heat-transfer analysis of animals: some implications for field ecology, physiology and evolution. In: Gates D, Schmerl RB (eds), Perspectives in biophysical ecology. Springer, Berlin Heidelberg New York
Belovsky GE (1978) Diet optimization in a generalist herbivore: the moose. Theor Pop Biol 14:105-134

Belovsky GE (1981) Optimal activity times and habitat choice of moose. Oecologia (Berlin) 48:22-30

Belovsky GE (1984a) Herbivore optimal foraging: new data and a comparison of three models. Am Nat 124:97-115

Belovsky GE (1984b) Snowshoe hare optimal foraging and its implications for population dynamics. Theor Pop Biol 25:235-264

Belovsky GE (1984c) Moose and snowshoe hare competition and a mechanistic explanation from foraging theory. Oecologia (Berlin) $61: 150-159$

Belovsky GE (1984d) Summer diet optimization by beaver. Amer Midl Nat 111:209-222

Belovsky GE (1986a) Generalist herbivore foraging and its role in competitive interactions. Am Zool 26:51-69

Belovsky GE (1986b) Optimal foraging and community structure: implications for a guild of generalist grassland herbivores. Oecologia (Berlin) 70:35-52

Bonner JT (1965) Size and cycle: an essay on the structure of biology. Princeton Univ Press, Princeton New Jersey

Calder WA III (1984) Size, function, and life history. Harvard University Press, Cambridge

Chappell MA (1983) Thermal limitations to escape responses in desert grasshoppers. Anim Behav 31 : 1088-1093

Conover WJ (1971) Practical nonparametric statistics. John Wiley, New York

Demment MW (1982) The scaling of ruminoreticulum size with body weight in East African ungulates. Afr J Ecol 20:43-47

Demment MW, Van Soest PJ (1981) Body size, digestive capacity and feeding strategies of herbivores. Winrock International Livestock Research Publication, Morrilton, Arkansas

Finch VA (1972a) Thermoregulation and heat balance of the east African eland and hartebeest. Amer J Physiol 222:1274-1379

Finch VA (1972b) Energy exchanges with the environment of two East African antelopes, the eland and the hartebeest. Symp Zool Soc London 31:315-326

Gates DM (1980) Biophysical ecology. Springer, Berlin Heidelberg New York

Glass NR (1967) A technique for fitting nonlinear models to biological data. Ecology 48:1010-1013

Hixon MA (1982) Energy maximizers and time minimizers: theory and reality. Am Nat 119:596-599

Hungate RE, Phillips GD, McGregor A, Hungate DP, Buechner HK (1959) Microbial fermentation in certain mammals. Science $130: 1192-1194$

Krebs JR, Davies NB (1978) Behavioural ecology: an evolutionary approach. Sinauer Associates, Inc., Sunderland, Massachusetts

Marquardt DW (1963) An algorithm for least-squares estimation of non-linear parameters. J Soc Ind App Math 11:431-441

McCollough YB (1980) Niche separation of seven North American ungulates on the National Bison Range, Montana. PdD Dissertation, Univ Michigan, Ann Arbor, Michigan

McNab BK (1963) A model of the energy budget of a wild mouse. Ecology 44:521-532

Moen AN (1973) Wildlife ecology: an analytical approach. WH Freeman and Co, San Francisco

Montieth JL (1973) Principles of environmental physics. American Elsevier Publishing Co, Inc., New York

Morhardt SS (1975) Use of climate diagrams to describe microhabitats occupied by Belding ground squirrels and to predict rates of change of body temperature. In: Gates D, Schmerl RB (eds), Perspectives in biophysical ecology. Springer, Berlin Heidelberg New York

Morhardt SS, Gates D (1974) Energy-exchange analysis of the Belding ground squirrel and its habitat. Ecol Mono 44:17-44

Parker MA (1982) Thermoregulation by diurnal movement in the barberpole grasshopper (Dactylotum bicolor). Amer Midl Nat $107: 228-237$

Peters RH (1983) The ecological implications of body size. Cambridge University Press, London

Porter WP, Mitchell JW, Beckman WA, DeWitt CB (1973) Behav- 
ioral implications of mechanistic ecology: thermal and behavioral modelling of desert ectotherms and their microenvironment. Oecologia (Berlin) 13:1-54

Porter WP, Mitchell JW, Beckman WA, Tracy CR (1975) Environmental constraints on some predator-prey interactions. In: D Gates, RB Schmerl (eds), Perspectives in biophysical ecology. Springer, Berlin Heidelberg New York

Pyke GH, Pulliam HR, Charnov EL (1977) Optimal foraging: a selective review of theory and tests. Quart Rev Biol 55:137-154

Schoener TW (1971) Theory of feeding strategies. Ann Rev Ecol Syst 2:369-403
Schoener TW (1974) The compression hypothesis and temporal resource partitioning. Proc Nat Acad Sci 71:4169-4172

Stower WJ, Griffiths JF (1966) The body temperature of the desert locus (Schistocerca gregaria). Ent exp appl 9:127-178

Tracy CR (1975) Water and energy relations of terrestrial amphibians: insights from mechanistic modeling. In: Gates D, Schmerl RB (eds), Perspectives in biophysical ecology. Springer, Berlin Heidelberg New York

Wilson DS (1975) The adequacy of body size as a niche difference. Am Nat 109:769-784

Received December 1, 1985 